\title{
Screening of Saccharomyces cerevisiae: A Strategy to Enhance Flavour of Jujube Liquor
}

\author{
Xiaolei Guan, Yaqiong Liu*, Yao Lu, Suwen Wang, Jingyu Jin, Jie Wang and Rongbin Li \\ College of Food Science and Technology, Hebei Agricultural University, Hebei, 071000, China
}

\author{
Article history \\ Received: 25-03-2020 \\ Revised: 14-05-2020 \\ Accepted: 16-07-2020 \\ Corresponding Author: \\ Yaqiong Liu \\ College of Food Science and \\ Technology, Hebei Agricultural \\ University, Hebei, 071000, \\ China \\ Email: lyqcau@126.com
}

\begin{abstract}
The main objective of this study was to isolate newly indigenous yeast strains from the fermentation of jujube liquor. 19 isolated yeast strains were obtained by spontaneous solid-state fermentation and flavour characteristics of the fermented jujube juice were also compared from above selected strains. 3 strains (JM-3, JM-13, JM-17) were screened out and identified as Saccharomyces cerevisiae (S. cerevisiae) by molecular identification. Tolerance tests for glucose, temperature, $\mathrm{pH}$ and alcohol of three yeast stains were compared. The result showed that the glucose tolerance of JM-3 was better those of JM-13 and JM-17, the temperature and $\mathrm{pH}$ tolerance were similarities in three yeast strains and the alcohol tolerance of JM-13 was better those of JM-3 and JM-17. Jujube juice was used as medium for single and mixed-culture fermentation with commercial S. cerevisiae G-1. All the important aroma compounds were detected in jujube juice fermented with JM-13+G-1 and JM-13 had an excellent potential starter for jujube liquor production.
\end{abstract}

Keywords: Saccharomyces cerevisiae, Jujube Liquor, Fermentation, Environmental Tolerance, Volatile Compounds

\section{Introduction}

Jujube (Ziziphusjujuba Mill.) has been widely developed in China in the past 10 years and according to the Statistics of China National Bureau of data and statistics (SSB, 2018), its production reached 7,357,600 metric tons. In China, jujube fruit is not only consumed in dried forms (Hong, 2006) but also processed into jujube preserves, juice, wine and vinegar. Jujube liquor is a kind of distilled spirit brewed by traditional solidstate fermentation technologies and has an alcohol content of $38-60 \%$. In jujube liquor production, jujube fruit is generally broken, mixed with rice husk and water, placed in an underground mud pit or cement pit for fermentation for approximately one month and finally distilled. Jujube liquor is welcomed by many consumers given its rich and unique jujube flavour. Moreover, this way of processing effectively reduces postharvest loss and increases the added value of jujube fruit.

Jujube liquor is mainly produced by spontaneous fermentation or inoculated with wine yeast, which is related to the quality and flavour instability. Although yeast screening in numerous studied for the improvement of the quality and flavour of wines and liquors, investigations on jujube liquor are few. Quan et al.
(2004) reported that two isolated S. cerevisiae strains from jujube and jujube orchard soil have good fermentation characteristics and produced jujube wine with outstanding aroma, full body and mellow taste. Two S. cerevisiae strains (Z13, Z14) were isolated and identified from jujube orchard soil and jujube fermentation broth by (Wang et al., 2015). Fermentation experiments revealed that the quality, taste, aroma and typical characteristics of jujube wine produced by these two strains are comparable or superior to those of wine produced using the Angel active dry yeast. The effects of five commercial $S$. cerevisiae strains on reducing sugar, total acidity and alcohol content of jujube wine were studied. Jujube wine fermented by the Laffort F15 strain have higher alcohol contents, lower fusel oil contents and more balanced fruity quality and bouquet than those brewed by the other yeasts (Jia et al., 2015). Furthermore, the total polyphenol content and antioxidant activity of jujube wine was affected by yeast strains (Guo et al., 2019; Zou et al., 2019). Sequential inoculation of non-Saccharomyces yeast $(\mathrm{H})$ and $S$. cerevisiae (RV171) can improve the flavour and quality of jujube wine (Jia et al., 2019).

Volatile flavour compounds play an important role in the organoleptic quality of jujube liquor and 
differentiating the product in the marketplace. A total of 52 volatile flavour compounds in jujube brandy (42\%vol) were identified by Gas ChromatographyOlfactometry-Mass Spectrometry (GC-O-MS) (Li et al., 2017). Solid Phase Microextraction (SPME) has also proven to be an effective technique for volatile aroma analysis (Zhang et al., 2008; Huang et al., 2012; Wang et al., 2012; Fan et al., 2012; Pu et al., 2011). A total of 118 volatile compounds were identified from jujube brandy by HS-SPME-GC/MS with the SPME fiber (50/30 $\mu \mathrm{m} \mathrm{CAR/DVB/PDMS)} \mathrm{(Xia} \mathrm{et} \mathrm{al.,} \mathrm{2014).}$ Moreover, HS-SPME-GC/MS combined olfactometry, aroma recombination and omission/addition tests were used in identifying and analyzing the volatile aroma compounds of jujube brandy (Ren et al., 2019). The results showed that ethyl octanoate is the characteristic aroma substance in jujube brandy and ethyl octanoate, ethyl valerate, butanol, 3-methyl-1-butanol and pentanoic acid play an important role in the overall aroma. Furthermore, (Song et al., 2019) found that most volatile compounds are mainly produced in the early stage of jujube brandy fermentation and their contents increase rapidly in the latter stages. The jujube brandy brewed with Daqu and yeast by solid-state fermentation has rich and unique flavour characteristics (Li et al., 2016).

In summary, $S$. cerevisiae can promote and enrich the flavour of jujube brandy/wine, but current strain screening methods are primarily used in jujube wine production and studies on jujube liquor are few. The objectives of the present work are to isolate $S$. cerevisiae strains from jujube grains during spontaneous solid-state fermentation, select and identify the strains by molecular identification and determine the growth characteristics and evaluate the environmental tolerance of the strains. Furthermore, jujube juice simulated fermentation experiments were performed for the comparison of the fermentation characteristics and flavour of selected and commercial $S$. cerevisiae. To the best of our knowledge, no report regarding the isolation of yeast strainfermented grain for jujube liquor production has been published previously.

\section{Materials and Methods}

\section{Yeast Strains, Media and Jujube}

All yeast strains were maintained at $4{ }^{\circ} \mathrm{C}$ on Yeast Extract Peptone Dextrose (YPD) agar medium (2\% glucose, $2 \%$ peptone, $1 \%$ yeast extract and 2\% agar). Commercial yeast (Angel high activity S. cerevisiae) was purchased from Angel Yeast Co., Ltd. (Hubei Province, China). Fuping jujube fruit was purchased from a local market (Baoding, China). Jujube juice Liquid fermentation Media (JLM) was prepared according to (Qi, 2018). Preliminary boiling for $30 \mathrm{~min}$ with a jujube fruit/distilled water ratio of $1: 10$, filtering with gauze and the supernatant was centrifuged at $7783 \times \mathrm{g}$ for $10 \mathrm{~min}$ with high speed freezing centrifuge at $4^{\circ} \mathrm{C}$ (H1650-W, Xiangyi Instrument Co., Ltd, China). Sugar content was standardized by adding sugar to $10^{\circ}$ Brix and $\mathrm{pH}$ value at a natural state. The media were sterilized in an autoclave at $121^{\circ} \mathrm{C}$ for $20 \mathrm{~min}$ before use.

\section{Isolation of Yeast Strains}

All strains were isolated from the various fermentation stages of jujube grains during spontaneous solid-state fermentation (Hebei Yuer Liquor Co., Ltd, China). $25 \mathrm{~g}$ of fermented grains were collected and transferred in $225 \mathrm{~mL}$ of $0.9 \%$ sterile saline and shaken at room temperature for $10 \mathrm{~min}$ at $150 \mathrm{rpm}$ and then $10^{5}$ fold dilutions were prepared in saline. From each dilution $200 \mu \mathrm{L}$ were plated in Petri dishes containing YPD agar medium. Petri dishes were incubated at $28^{\circ} \mathrm{C}$ for 24-72 h until colony development. Only the isolates that presumptively belonged to the species $S$. cerevisiae were purified by repetitive streaking on YPD agar medium by (Suzzi et al., 2012). The isolated yeast strains were cultured in $100 \mathrm{~mL}$ of YPD and incubated at $28^{\circ} \mathrm{C}$ for $24 \mathrm{~h}$. Then, the strains were transferred to the JLM at a $2 \%$ inoculum amount and the volatile compounds of the broth were determined by HS-SPMEGC-MS after incubation for 6 days at $28^{\circ} \mathrm{C}$. Strains that showed relatively high aroma production in the volatile compounds compared with similar species were selected. A jujube juice liquid fermentation medium without inoculation was used as the control group.

\section{Molecular Identification of Yeast Strains}

Genome DNA was extracted using a DNA kit (D3390-02, OMEGA) according to the manufacturer's instructions. The primer pair ITS1 (5'TCCGTAGGTGAACCTGCGG-3') and ITS4 (5'TCCTCCGCTTATTGATATGC-3') were used for PCR. The PCR mix consisted of $\mathrm{ddH}_{2} \mathrm{O}(36.5 \mu \mathrm{L}), 10 \times$ Ex Taq buffer $(5.0 \mu \mathrm{L}), 2.5 \mathrm{mM}$ dNTP $(4.0 \mu \mathrm{L}), 10 \mathrm{p}$ primer $(2.0$ $\mu \mathrm{L})$, a template $(2.0 \mu \mathrm{L})$ and $5 \mathrm{u} \operatorname{Ex} \operatorname{Taq}(0.5 \mu \mathrm{L})$. The PCR cycling program for DNA amplification was performed as described by (Wang et al., 2019) consisted of one cycle at $94^{\circ} \mathrm{C}$ for $3 \mathrm{~min}, 35$ cycles at $94^{\circ} \mathrm{C}$ for 30 $\mathrm{s}, 55^{\circ} \mathrm{C}$ for $30 \mathrm{~s}$ and final 35 cycles at $72^{\circ} \mathrm{C}$ for $1 \mathrm{~min}$. The resulting sequences were subjected to Blast (http://www.ncbi.nlm.nih.gov/BLAST) homologous alignment in the NCBI database.

\section{Determination of Fermentation Characteristics of Yeast Strains}

The isolated yeast strains were activated in $0.9 \%$ saline for $24 \mathrm{~h}$, then inoculated in YPD medium at a $2 \%$ inoculum amount. The yeast strains were cultured at a constant temperature of $28^{\circ} \mathrm{C}$ and the $\mathrm{OD}$ value of the 
fermentation broth was measured at $600 \mathrm{~nm}$ with a UV spectrophotometer $(\alpha-1500$, Shanghai Puyuan Instrument Co., Ltd) every $1 \mathrm{~h}$. The growth curve was drawn with incubation time (h) as abscissa and OD600nm (A) as ordinate. The alcohol production capacity of yeasts was determined by $\mathrm{CO}_{2}$ weight loss (Xin, 2018). The curve was drawn with $\mathrm{CO}_{2}$ weightlessness $(\mathrm{g})$ as ordinate and time (d) as abscissa.

\section{Determination of Environmental Tolerance of Yeast Strains}

The glucose, temperature, $\mathrm{pH}$ and ethanol stress tolerance of the selected yeast stains were analyzed according to the mothed of (Zhang et al., 2018). Exactly $10 \mathrm{~mL}$ of each YPD medium was inoculated with $200 \mu \mathrm{L}$ of yeast suspension from an initial concentration of $1 \times 10^{8}$ $\mathrm{CFU} / \mathrm{mL}$ of each yeast strains. Glucose tolerance was achieved by supplementing each medium with $30 \%, 40 \%$, $50 \%, 60 \%, 65 \%$ and $70 \%(\mathrm{w} / \mathrm{v})$ of glucose. Temperature assays were performed by incubating YPD medium at different temperature conditions $\left(12^{\circ} \mathrm{C}, 14^{\circ} \mathrm{C}, 16^{\circ} \mathrm{C}, 38^{\circ} \mathrm{C}\right.$, $43^{\circ} \mathrm{C}$ and $\left.48^{\circ} \mathrm{C}\right) \cdot \mathrm{pH}$ tolerance was determined by adding hydrochloric acid $(1 \mathrm{~mol} / \mathrm{L})$ to YPD medium until the final $\mathrm{pH}$ reached $1.5,2.0,2.5,3.0,3.5$ and 4.0 respectively. Alcohol tolerance test was conducted by increasing concentrations of ethanol until final concentrations of 10 , $13,16,19,22$ and $25 \%$ (v/v) were obtained. All assays were incubated at $28^{\circ} \mathrm{C}$ for $36 \mathrm{~h}$ and performed in triplicate. OD600 was measured and finally recorded.

\section{Simulated Fermentation}

To confirm the effect of Saccharomyces yeasts on fermented jujube juice quality, the fermentation experiments were performed as described by (Jia et al., 2015) with modifications. Each juice was fermented by a single-culture of the selected yeast strains and a mixedculture of selected Saccharomyces yeast and commercial S. cerevisiae G-1 at a $20: 1(\mathrm{v} / \mathrm{v})$ ratio at $28^{\circ} \mathrm{C}$ for 6 days. Fermentation was performed in a JLM where total yeast inoculation was controlled at $1 \times 10^{8} \mathrm{CFU} / \mathrm{mL}$. The control group was fermented by a single-culture of $S$. cerevisiae $\mathrm{G}-1$. Test was conducted in triplicate.

\section{Analysis of Fermented Jujube Juice Characteristics}

All the samples were centrifuged $(7783 \times \mathrm{g}$ for $10 \mathrm{~min})$ for the analysis of fermented jujube juice characteristics (Settanni et al., 2012). Soluble solid was analyzed using a refractometer according to AOAC guidelines. The $\mathrm{pH}$ was measured using a pH meter (Model 340, Mettler Toledo Gmb H, Schwerzenbach, Switzerland) and the titratable acidity (expressed as $\mathrm{g} \mathrm{kg}^{-1}$ tartaric acid) was determined using the AOAC Official Method 962.12.

Ethanol contents were determined using an Agilent Model 7890B GC with reference to the national standard GB 5009.225-2016 (SAC, 2016) published by the
Standardization Administration of China. Briefly, the fermentation broth was filtered by organic membrane $(0.45 \mu \mathrm{m}, \mathrm{PTFE})$ and then put into gas phase vial $(2 \mathrm{~mL}$, 9-425 transparent thread chromatographic injection vial). Chromatographic conditions are as follows: Agilent HPINNOWax column $(60 \mathrm{~m} \times 0.25 \mathrm{~mm} \times 0.25 \mu \mathrm{m}$, Agilent $\mathrm{J} \& \mathrm{~W}$, USA); column temperature, $50^{\circ} \mathrm{C}$; temperature of gasifier and detector, $240^{\circ} \mathrm{C}$, carrier gas (high purity nitrogen) flow rate, $30 \mathrm{~mL} / \mathrm{min} ; \mathrm{H}_{2}$ flow rate, 30 $\mathrm{mL} / \mathrm{min}$; air flow rate, $300 \mathrm{~mL} / \mathrm{min}$. Ethanol were detected using a FID detector.

\section{Volatile Compound Analysis}

The volatile compounds of the fermented jujube juice were determined by HS-SPME-GC-MS according to the methods described by $\mathrm{Hu}$ et al. (2018). Briefly, the volatiles were extracted with a SPME fiber $(50 / 30 \mu \mathrm{m}$ DVB/CAR/PDMS; Supelco, Bellefonte PA, USA). The fermentation broth $(7.5 \mathrm{~mL}), 3$-octanol $(300 \mathrm{mg} / \mathrm{L}, 20$ $\mu \mathrm{L})$ and $1 \mathrm{~g} \mathrm{NaCl}$ were held in a gas-tight vial $(20 \mathrm{~mL}$, PTFE/silicon septum, magnetic cap), kept at equilibrium in a $40^{\circ} \mathrm{C}$ water bath with stirring for $15 \mathrm{~min}$, extracted for $40 \mathrm{~min}$ and then desorbed in the $\mathrm{GC}$ injector at $240^{\circ} \mathrm{C}$ for 6 min using a Agilent $7890 \mathrm{~B}$ GC coupled with an Agilent 5977A MS (Aglient, USA). Agilent HPINNOWax column $(60 \mathrm{~m} \times 0.25 \mathrm{~mm} \times 0.25 \mu \mathrm{m}$, Agilent J\&W, USA) was used. Injection was splitless with 5.8 min relay time. Helium was the carrier gas with a flow rate of $1 \mathrm{~mL} / \mathrm{min}$. The $\mathrm{GC}$ program involved an initial temperature $50^{\circ} \mathrm{C}$ raised to $80^{\circ} \mathrm{C}$ at $3^{\circ} \mathrm{C} / \mathrm{min}$, raised to $230^{\circ} \mathrm{C}$ at $5^{\circ} \mathrm{C} / \mathrm{min}$ and maintained at $230^{\circ} \mathrm{C}$ for $6 \mathrm{~min}$. The MS conditions were set as follows: Electron impact mode at $70 \mathrm{eV}$, temperature of $230^{\circ} \mathrm{C}$ and total ion current scanning range of $45-550 \mathrm{~m} / \mathrm{z}$.

Qualitative analysis: The NIST 14 library was used for comparison, the internal standard method was used for quantification and the components with a matching degree of more than $80 \%$ were analyzed (González Álvarez et al., 2011).

\section{Statistical Analysis}

All data were analysed using SPSS 23.0 with Duncan test and the level of significance was set to $P<0.05$. The reported results are mean values \pm standard deviation of triplicates.

\section{Results and Discussion}

\section{Isolation and Screening of Saccharomyces cerevisiae}

There were 19 yeast strains isolated from jujube grains. The compositions and concentrations of the volatile flavour compounds of jujube liquor have been of great interest because of their influence on sensory properties and consumer acceptance. In our previous research, ethyl caproate, ethyl caprylate, ethyl caprate, 
ethyl laurate, damascenone and phenylethyl alcohol have important contributions to the flavour of jujube brandy (Xia et al., 2015). As shown in Fig. 1A, flavour composition was affected by yeast strains. All these compounds in JLM with yeast strains were much higher than that of the control. The contents of ethyl caprylate, ethyl caprate, ethyl laurate and damascenone of JLM fermented by JM-3, JM-13 and JM-17 were higher than those of other yeasts. Moreover, JM-3 and JM-17 had higher ethyl caproate contents than other strains and the phenethyl alcohol contents of the three strains were relatively high. Further, the volatile compounds contents of JLM inoculated with each strain were showed in supplementary Table 1. Dissimilarities among the different samples with respect to flavour profile were determined through PCA. The results in Fig. 1B indicate appreciable differences among the samples. The strains JM-3, JM-13 and JM-17 were in the same quadrant as ethyl caproate, ethyl caprate and ethyl laurate. All these compounds were strongly correlated with the JM-3 strain and located in the positive position of the PC1 axis. Hence, these three strains were selected for the subsequent experiment.

\section{Identification Result}

The molecular identification of three isolated yeast strains was performed in Majorbio Bio-Pharm Technology Co., Ltd. (Shanghai, China). The sequencing results were entered into the NCBI database for blast homology alignment and the ITS sequences with high homology were obtained. The results are shown in Table 1. According to the Blast homology alignment of the NCBI database, the three yeast strains JM-3, JM-13 and JM-17 were $S$. cerevisiae.

\section{Growth Characteristics}

The growth rate of high-quality yeast was relatively fast and such feature is of great significance to the selection of excellent yeast strains for the production of high-quality liquor. The growth curve of yeast can accurately reflect the growth rule of strains. Figure $2 \mathrm{a}$ shows that the growth curves of the three yeasts were " $S$ " curves. The three curves basically coincided in the first $5 \mathrm{~h}$. At this stage, the yeast was in the adjustment period and strain JM-3 entered the exponential phase at 8 h. During this phase, the strain had the strongest activity and most vigorous growth and it enters the stable phase at $17 \mathrm{~h}$. Conversely, JM-13 and JM-17 started slowly, entered the exponential phase at $10 \mathrm{~h}$ and the stable phase at $17 \mathrm{~h}$. The metabolism of the yeast cells in different growth periods obviously differed and had distinct characteristics. For example, the metabolism of amino acids was vigorous in the exponential phase but decreased in the stable phase (Diaz-Camino et al., 2003). In jujube liquor brewing, the efficient production of ethanol is inseparable from the large-scale reproduction of $S$. cerevisiae. Therefore, an earlier entry to the logarithmic phase is more favorable for fermentation. In summary, JM-3 has the advantages of fast fermentation speed and long logarithmic growth period compared with the other two strains.

The weight loss of $\mathrm{CO}_{2}$ can reflect the fermentation rate of a strain and indirectly indicates the strength of the fermentation capacity of the strain. Figure $2 \mathrm{~b}$ suggests that with the increases of days, the daily $\mathrm{CO}_{2}$ weight loss of the three strains were increased and the $\mathrm{CO}_{2}$ loss weight of JM-3 and JM-13 were almost exactly coincident but was slightly lower than that of JM-17 at first. The $\mathrm{CO}_{2}$ loss weight of JM-3 increased rapidly on the Day 3 and surpassed the other two strains on Day 6 . On Day 14, the OD value of the three yeast strains tended to be gentle. The $\mathrm{CO}_{2}$ weightlessness of JM-3 and JM-17 were significantly higher than that of JM-13 on Day 15 of fermentation $(P<0.05)$. Meanwhile, strains JM-3 and JM-13 had the maximum and minimum $\mathrm{CO}_{2}$ weightlessness of $3.972 \pm 0.061 \mathrm{~g}$ and $3.332 \pm 0.022 \mathrm{~g}$, respectively. The aforementioned study showed that the fermentation rate of wine inoculated with different yeast strains was affected by the weight loss of $\mathrm{CO}_{2}$ during fermentation and that a higher $\mathrm{CO}_{2}$ weight loss meant a faster fermentation rate (Wang, 2019a).

\section{Environmental Tolerance Analysis}

Glucose concentration has significant consequences on the adaptation of fermentative yeast strains (Wang, $2019 b$ ). Figure 3 a shows that the OD values of strains JM-3 and JM-13 were gradually reduced with the increase of glucose concentration. The OD value of JM17 decreases first from 30 to $40 \%$ of glucose concentration, then increases from 40 to $50 \%$ and decreases gradually afterwards. The growth rate of JM-3 was significantly higher than that of JM-13 and JM-17 when glucose concentration was $30 \%(P<0.05)$ and its OD value was $0.858 \pm 0.022$. The growth rate of the three yeast strains was strongly inhibited and almost stopped when the glucose concentration was $70 \%$. The initial sugar content of jujube fermentation grain was 20-30\%. Therefore, the glucose tolerance of the three yeast strains can meet the needs of brewing jujube liquor.

Table 1: Higher homologous strains downloaded from GenBank

\begin{tabular}{lllll}
\hline Isolate & Size of fragments (bp) & GenBank & Strain & Matching degree \\
\hline JM-3 & 933 & KU350743.1 & Saccharomyces cerevisiae & $99 \%$ \\
JM-13 & 895 & KU350743.1 & Saccharomyces cerevisiae & $100 \%$ \\
JM-17 & 758 & KU350743.1 & Saccharomyces cerevisiae & $99 \%$ \\
\hline
\end{tabular}




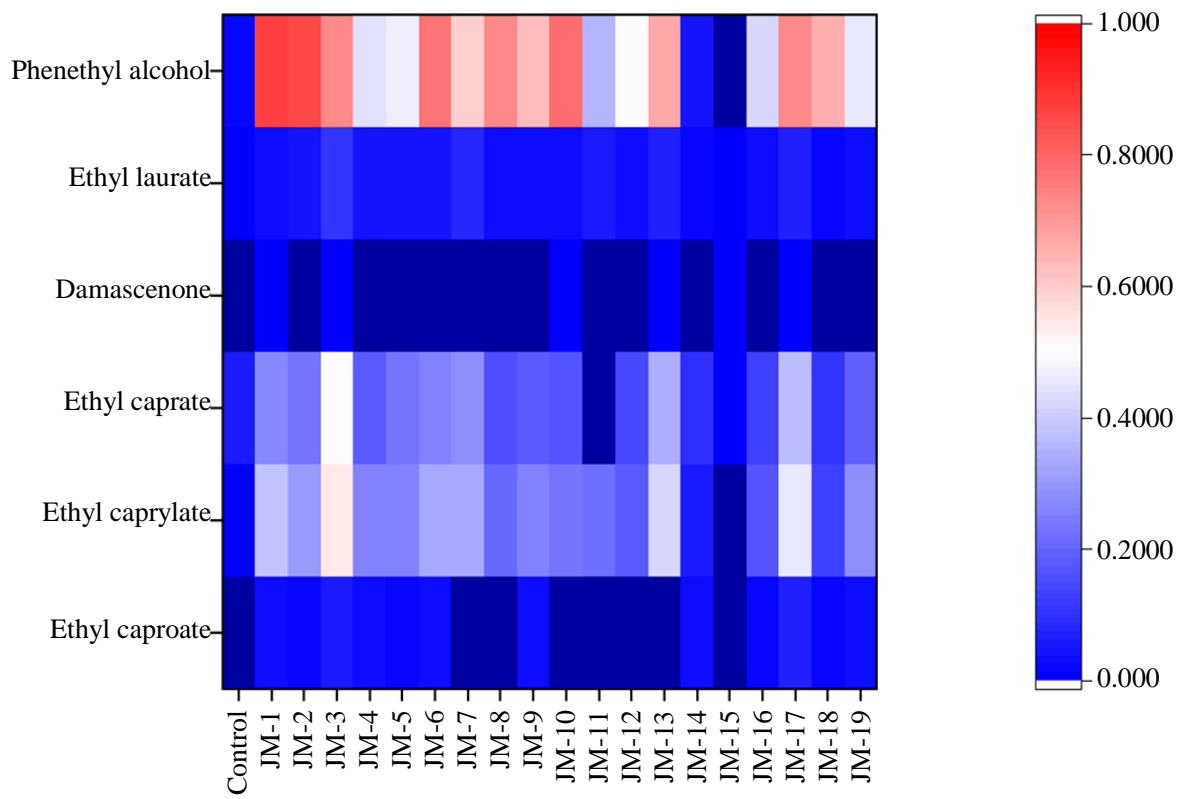

(A)

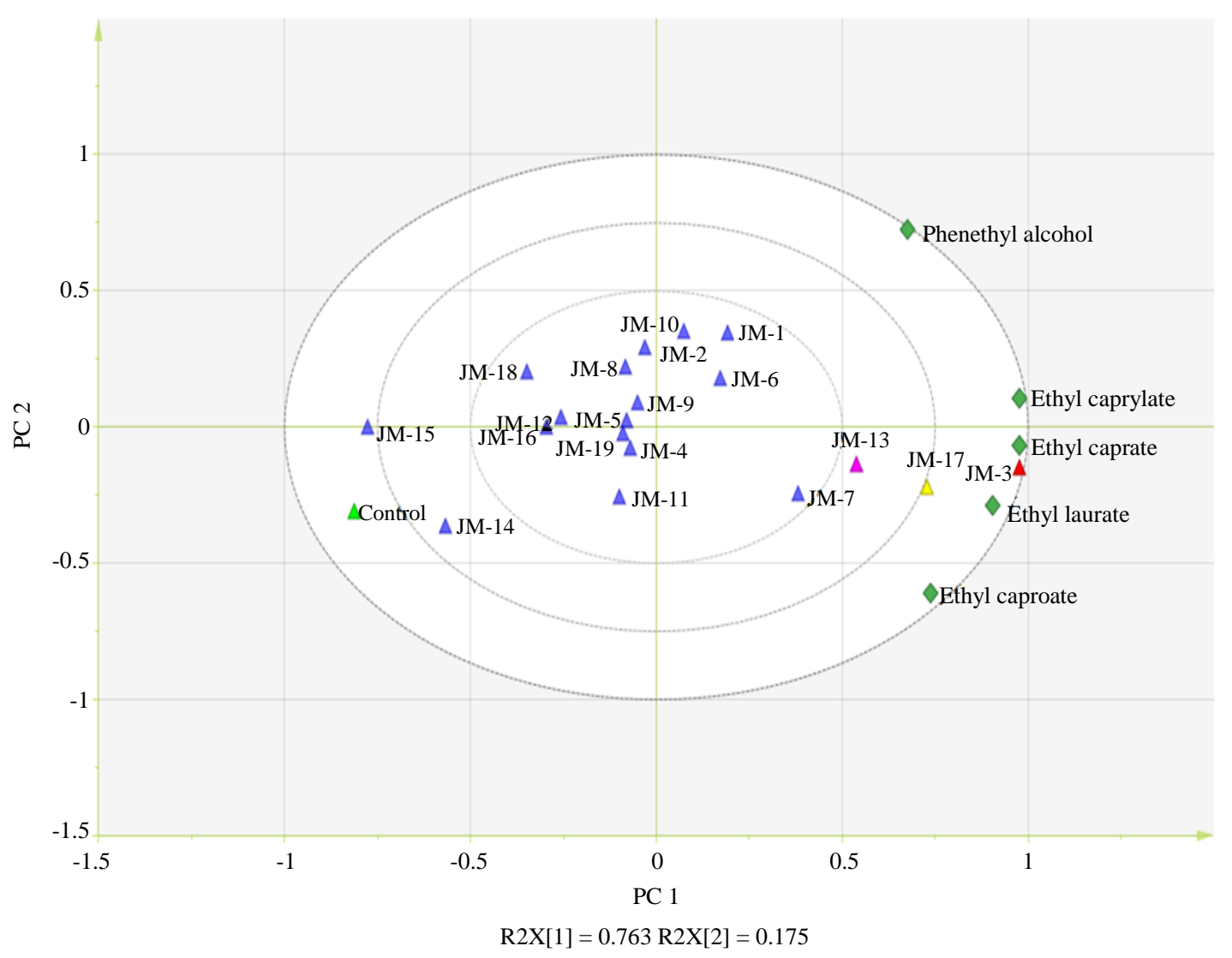

(B)

Fig. 1: (A) Heat map of important flavour compounds identified in broth with different fermentation yeast strains. (B): PCA plot based on the variable change of volatile components concentration in different yeast strains of fermentation juice. Samples are represented in the score plots by different symbols and colors 

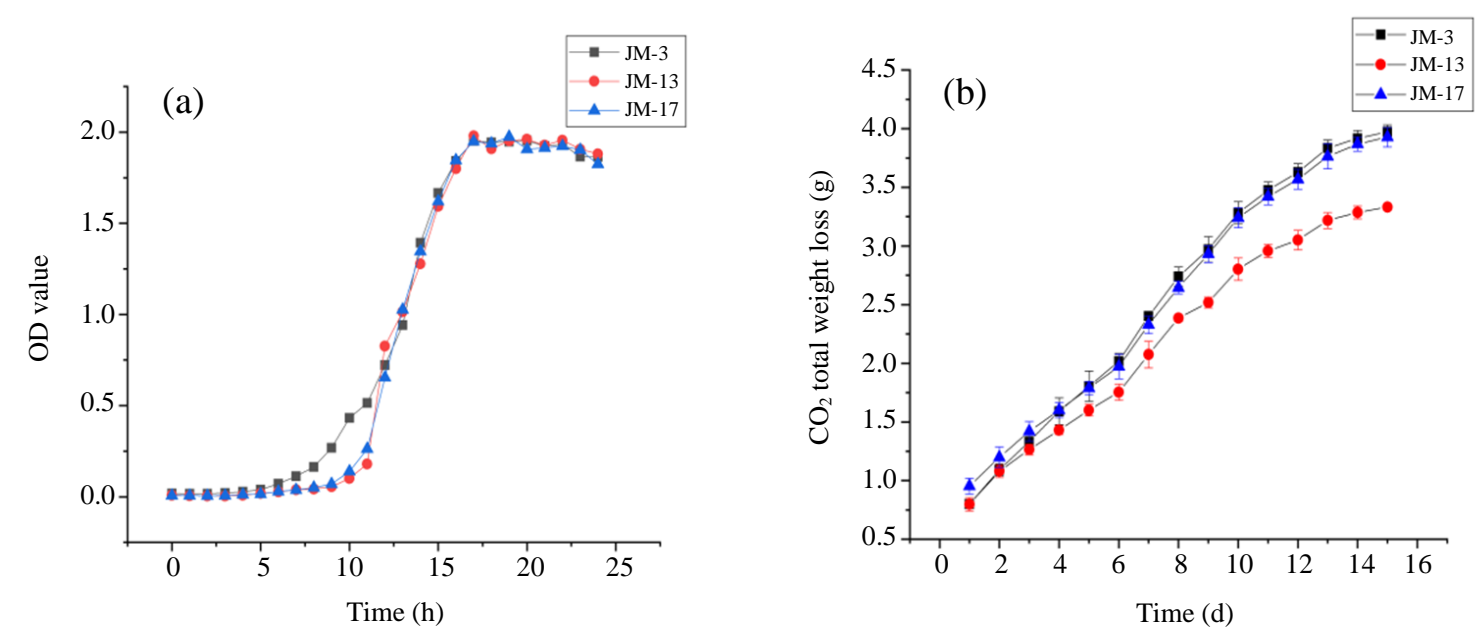

Fig. 2: Yeast growth curve (a) $\mathrm{CO}_{2}$ weightlessness (b)
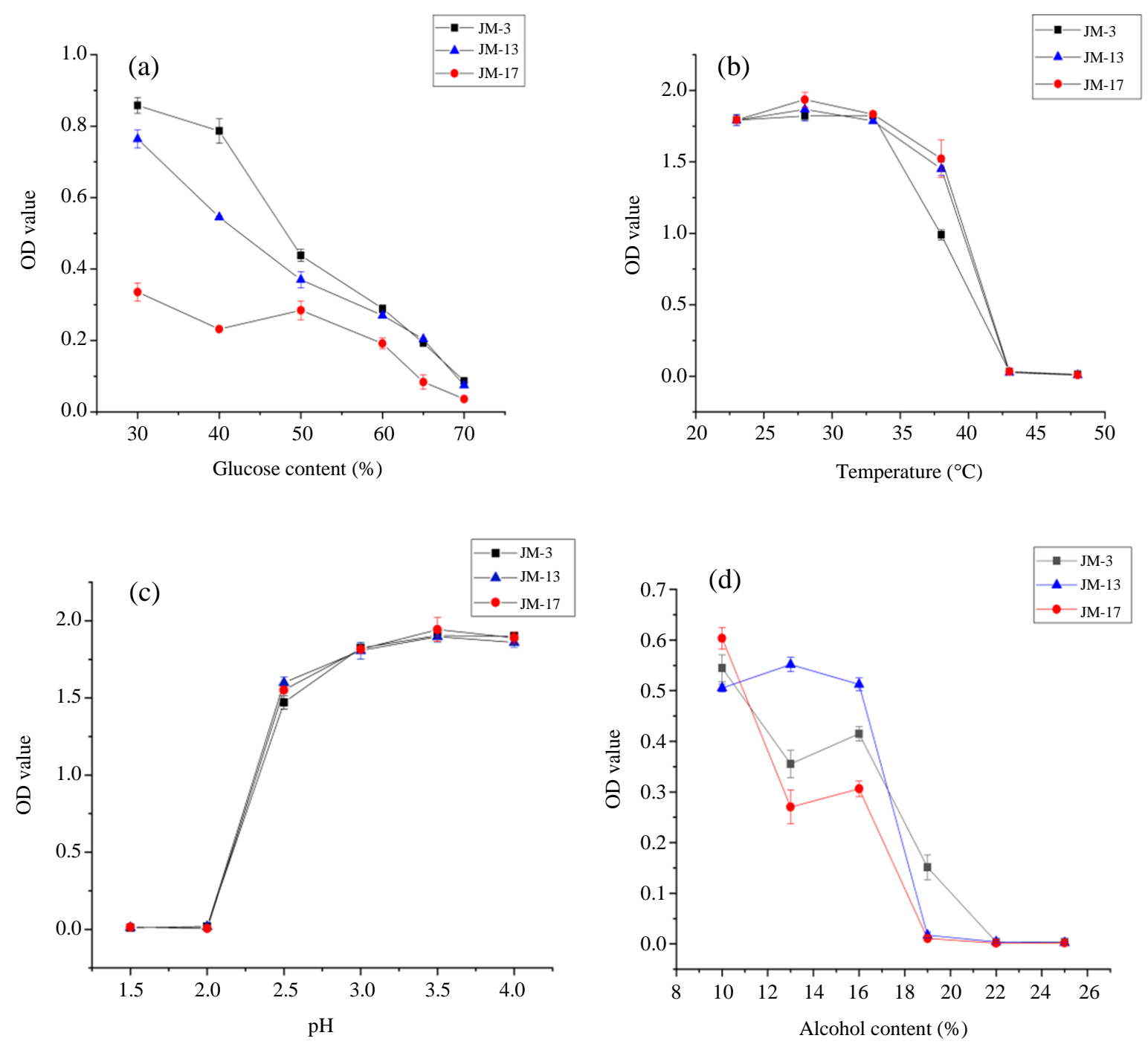

Fig. 3: Glucose tolerance (a), temperature tolerance (b), pH tolerance(c), Alcohol tolerance (d) test of yeast strains 
The common belief is that $20-35^{\circ} \mathrm{C}$ is the ideal range for fermentation and fermentation at higher temperatures would be problematic (Moreno et al., 2012; Ballesteros et al., 2004; Muenduen et al., 2006). As shown in Fig. 3b, the activity of yeast strains was inhibited with the increase of temperature. The optimal growth temperature of the three yeast strains was $23-33^{\circ} \mathrm{C}$, which was consistent with the optimal growth temperature of most yeast strains. When the temperature exceeded $33^{\circ} \mathrm{C}$, the OD values of the three yeast strains were sharply decreased. The OD values of JM-13 and JM17 were significantly higher than that of $\mathrm{JM}-3$ at $38^{\circ} \mathrm{C}$ $(P<0.05)$. When the temperature was beyond $43^{\circ} \mathrm{C}$, the growths of the three yeast strains were stagnant. Therefore, fermentation should be carried out at a suitable temperature to ensure the activity of yeast strains.

Figure $3 \mathrm{c}$ shows that the OD values of the three yeast strains gradually increased with the increase of $\mathrm{pH}$ and reached the maximum at $\mathrm{pH} 3.5$. The change tendencies of the three yeast strains were almost the same. Moreover, the growths of the three yeast strains were almost stopped when the $\mathrm{pH}$ was 1.5 to 2.0 and the growth rates of the yeast strains increased rapidly from $\mathrm{pH} 2.0$ to 2.5 . The OD value of strain JM-13 was significantly higher than those of JM-3 and JM-17 at $\mathrm{pH}$ $2.5(P<0.05)$. When the $\mathrm{pH}$ was 3.0 to 4.0 , the trends in the OD values of the three yeast strains were basically the same and tended to be stable. Therefore, the three yeast strains were suitable for growth at $\mathrm{pH}$ 2.5-4.0.

Alcohol tolerance is an important target to evaluate the performance of yeast. Figure $3 d$ reveals that the growth rates of JM-3 and JM-17 declined from 10 to $13 \%$ of alcohol content, then increased from 13 to $16 \%$ afterwards and decreased significantly and finally stopped at 19 and $22 \%$ of alcohol content, respectively $(P<0.05)$. Conversely, the growth activity of JM-13 increased from 10 to $13 \%$ of alcohol content and then decreased and its OD value reached a maximum value when the alcohol content was $13 \%$. The OD values of the three yeast strains sharply decreased when the alcohol content was from 16 to $19 \%$. Strain JM-13 hardly grew while the alcohol content reached $19 \%$. The OD value of JM-17 was significantly higher than that of JM-3 and JM-13 at 10\% of alcohol content. However, at $13-16 \%$, the three yeast strains had significant differences. Strain JM-13 had the highest OD value. Birch and Walker (2000) proposed that high ethanol concentrations reduce cell viability and increase cell death of $S$. cerevisiae. Therefore, JM-13 had better alcohol tolerance than JM-3 and JM-17.

In the previous findings, 8 strains of $S$. cerevisiae isolated from orchard soil, fruit and epidermis with better fermentation performance were tested for the tolerance of alcohol, citric acid and glucose by (Zhang et al., 2018). The results showed that $\mathrm{Y}-2$ and F-3 could start fermentation quickly under $400 \mathrm{~g} / \mathrm{L}$ glucose, $16 \%$ alcohol and $20 \mathrm{~g} / \mathrm{L}$ citric acid. In another study by (Duan, 2012), S. cerevisiae J12 were able to survive in $400 \mathrm{~g} / \mathrm{L}$ of glucose, $15 \%$ of alcohol and temperature of $15-35^{\circ} \mathrm{C}$. Similar to those results, the strains JM-3 and JM-13 were fermented quickly under $40 \%$ glucose, temperature of $23-38^{\circ} \mathrm{C}, \mathrm{pH} 3.5$ and $16 \%$ alcohol. The tolerance of strain JM-17 was relatively poor, it was able to survive in $30 \%$ of glucose and $10 \%$ of alcohol.

\section{Effect of Saccharomyces Yeasts on Jujube Juice Characteristics}

The fermentation characteristics of jujube juice single-fermented with Saccharomyces yeasts or mixedfermented with both Saccharomyces yeasts chosen by the previous selection procedures and commercial $S$. cerevisiae G-1 are shown in Table 2 . In the results of jujube juice, the $\mathrm{pH}$ and titratable acid of all jujube juice were $3.9-4.2$ and $2.2-2.7 \mathrm{~g} / \mathrm{kg}$, respectively. The jujube juice fermented by stain JM-3 had the highest titratable acid of $2.577 \pm 0.025 \mathrm{~g} / \mathrm{kg}$ except G-1 and the lowest $\mathrm{pH}$ was at $3.993 \pm 0.025$. Zou et al. (2019) reported that different kinds of $S$. cerevisiae have little effect on the acidity of Jun-jujube wine. In this study, the $\mathrm{pH}$ and titratable acid of jujube juice fermented by different yeast strains also had no significant differences. Moreover, the soluble solid contents of jujube juice fermented by single fermentation were slightly higher than those of the control $(P<0.05)$. The alcohol content of mixed fermentation solution with strain JM-13+G-1 had relatively high alcohol content of $5.969 \pm 0.248 \%$ but lower than that of the control. Kim et al. (2019) found that the alcohol content of persimmon wine and apple cider inoculated with commercial $S$. cerevisiae was higher than those inoculated with selected yeast strains.

Table 2: Physicochemical properties of the jujube juice fermented with single or co-culture of Saccharomy cescerevisiae such as JM-3, JM-13, JM17 and commercial S. cerevisiae G-1

\begin{tabular}{|c|c|c|c|c|c|c|c|}
\hline \multirow[b]{2}{*}{ Property } & \multicolumn{7}{|l|}{ Strains } \\
\hline & G-1 & $\mathrm{JM}-3$ & JM-13 & JM-17 & G-1+JM-3 & G-1+JM-13 & G-1+JM-17 \\
\hline Alcohol (\% v/v) & $6.052 \pm 0.264^{\mathrm{a}}$ & $4.843 \pm 0.388^{\mathrm{bc}}$ & $3.584 \pm 0.499^{\mathrm{d}}$ & $4.608 \pm 0.567^{\mathrm{c}}$ & $5.512 \pm 0.323^{\mathrm{ab}}$ & $5.969 \pm 0.248^{\mathrm{a}}$ & $4.558 \pm 0.371^{\mathrm{c}}$ \\
\hline $\mathrm{pH}$ & $4.007 \pm 0.051^{\mathrm{c}}$ & $3.993 \pm 0.025^{\mathrm{c}}$ & $4.083 \pm 0.038^{\mathrm{ab}}$ & $4.057 \pm 0.035^{\mathrm{abc}}$ & $4.013 \pm 0.006^{\mathrm{bc}}$ & $4.043 \pm 0.021^{\mathrm{abc}}$ & $4.113 \pm 0.064^{\mathrm{a}}$ \\
\hline Soluble solid ( ${ }^{\circ}$ Brix) & $3.133 \pm 0.115^{\mathrm{d}}$ & $3.333 \pm 0.058^{\mathrm{bc}}$ & $3.533 \pm 0.115^{\mathrm{a}}$ & $3.400 \pm 0.100^{\mathrm{ab}}$ & $3.167 \pm 0.058^{\mathrm{cd}}$ & $3.167 \pm 0.058^{\mathrm{cd}}$ & $3.533 \pm 0.115^{\mathrm{a}}$ \\
\hline
\end{tabular}

Different letters within the same horizontal line indicate significant difference $(P<0.05)$ 
Table 3: Volatile component of the jujube wine fermented with single or co-culture of Saccharomyces cerevisiae such as JM-3, JM-13, JM-17 and commercial S. crevisiae G-1

\begin{tabular}{|c|c|c|c|c|c|c|c|}
\hline Compounds(mg/L) & G-1 & JM-3 & JM-13 & JM-17 & G-1+JM-3 & G-1+JM-13 & G-1+JM-17 \\
\hline Esters & $0.390 \pm 0.004^{b}$ & $0.120 \pm 0.014^{b}$ & $0.17 \pm 0.020^{b}$ & $0.24 \pm 0.062^{b}$ & $0.28 \pm 0.015^{b}$ & $0.63 \pm 0.121^{a}$ & $0.48 \pm 0.039^{\mathrm{ab}}$ \\
\hline Ethyl caproate & & & $0.027 \pm 0.002^{\mathrm{b}}$ & $0.063 \pm 0.010^{\mathrm{a}}$ & & $0.082 \pm 0.011^{\mathrm{a}}$ & $0.060 \pm 0.002^{\mathrm{a}}$ \\
\hline Ethyl caprylate & $0.023 \pm 0.001^{\mathrm{c}}$ & $0.025 \pm 0.003^{\mathrm{c}}$ & $0.018 \pm 0.004^{\mathrm{c}}$ & $0.070 \pm 0.006^{\mathrm{b}}$ & $0.052 \pm 0.000^{\mathrm{b}}$ & $0.106 \pm 0.015^{\mathrm{a}}$ & $0.118 \pm 0.022^{\mathrm{a}}$ \\
\hline Ethyl caprate & $0.025 \pm 0.002^{\mathrm{c}}$ & $0.028 \pm 0.002^{\mathrm{c}}$ & $0.026 \pm 0.007^{\mathrm{c}}$ & $0.028 \pm 0.006^{\mathrm{c}}$ & $0.047 \pm 0.003^{\mathrm{b}}$ & $0.054 \pm 0.017^{\mathrm{ab}}$ & $0.071 \pm 0.008^{\mathrm{a}}$ \\
\hline Ethyl 9-decenoate & & & & $0.017 \pm 0.003^{\mathrm{ab}}$ & & $0.011 \pm 0.002^{\mathrm{b}}$ & $0.020 \pm 0.004^{\mathrm{a}}$ \\
\hline Ethyl laurate & & $0.019 \pm 0.002^{\mathrm{b}}$ & $0.008 \pm 0.001^{\mathrm{bc}}$ & $0.007 \pm 0.001^{\mathrm{c}}$ & & $0.106 \pm 0.009^{\mathrm{a}}$ & \\
\hline Ethyl 3-phenylpropionate & $0.088 \pm 0.001^{\mathrm{b}}$ & $0.037 \pm 0.003^{\text {cd }}$ & $0.059 \pm 0.004^{c}$ & $0.027 \pm 0.003^{\mathrm{d}}$ & $0.099 \pm 0.004^{\mathrm{ab}}$ & $0.118 \pm 0.027^{\mathrm{a}}$ & $0.103 \pm 0.020^{\mathrm{ab}}$ \\
\hline Acids & $0.204 \pm 0.020^{b}$ & $0.069 \pm 0.009^{d}$ & $0.213 \pm 0.013^{b}$ & $0.123 \pm 0.011^{c}$ & $0.111 \pm 0.005^{c}$ & $0.208 \pm 0.011^{b}$ & $0.375 \pm 0.054^{\mathrm{a}}$ \\
\hline Acetic acid & & & $0.015 \pm 0.003^{\mathrm{a}}$ & $0.013 \pm 0.002^{\mathrm{a}}$ & & $0.011 \pm 0.002^{\mathrm{a}}$ & $0.012 \pm 0.002^{\mathrm{a}}$ \\
\hline Hexanoic acid & & & $0.020 \pm 0.006^{\mathrm{a}}$ & $0.018 \pm 0.000^{\mathrm{ab}}$ & $0.010 \pm 0.001^{\mathrm{b}}$ & $0.018 \pm 0.004^{\mathrm{ab}}$ & $0.026 \pm 0.004^{\mathrm{a}}$ \\
\hline Octanoic acid & $0.090 \pm 0.000^{\mathrm{b}}$ & $0.035 \pm 0.006^{\mathrm{c}}$ & $0.095 \pm 0.005^{\mathrm{b}}$ & $0.062 \pm 0.004^{\mathrm{bc}}$ & $0.062 \pm 0.004^{\mathrm{bc}}$ & $0.100 \pm 0.000^{\mathrm{b}}$ & $0.156 \pm 0.043^{\mathrm{a}}$ \\
\hline Decanoic acid & $0.113 \pm 0.019^{b}$ & $0.034 \pm 0.003^{\mathrm{d}}$ & $0.084 \pm 0.013^{\mathrm{c}}$ & $0.036 \pm 0.003^{\mathrm{d}}$ & $0.046 \pm 0.002^{\mathrm{d}}$ & $0.079 \pm 0.006^{\mathrm{c}}$ & $0.181 \pm 0.006^{\mathrm{a}}$ \\
\hline Alcohols & $1.393 \pm 0.059^{c}$ & $0.585 \pm 0.094^{d}$ & $1.514 \pm 0.139^{c}$ & $1.572 \pm 0.251^{c}$ & $2.412 \pm 0.236^{a b}$ & $2.087 \pm 0.240^{b}$ & $2.534 \pm 0.166^{a}$ \\
\hline 3-methyl-1-butanol & & & $0.331 \pm 0.044$ & $0.330 \pm 0.047$ & & & \\
\hline 1-Heptanol & & & & $0.006 \pm 0.001^{\mathrm{b}}$ & & $0.011 \pm 0.002^{\mathrm{a}}$ & $0.008 \pm 0.001^{\mathrm{ab}}$ \\
\hline 1-Octanol & & & $0.005 \pm 0.001^{\mathrm{b}}$ & & & $0.013 \pm 0.001^{\mathrm{a}}$ & $0.012 \pm 0.001^{\mathrm{a}}$ \\
\hline Phenylethyl Alcohol & $1.393 \pm 0.059^{\mathrm{c}}$ & $0.514 \pm 0.052^{\mathrm{d}}$ & $1.169 \pm 0.084^{\mathrm{c}}$ & $1.235 \pm 0.202^{\mathrm{c}}$ & $2.412 \pm 0.236^{\mathrm{a}}$ & $2.060 \pm 0.239^{\mathrm{b}}$ & $2.512 \pm 0.177^{\mathrm{a}}$ \\
\hline Aldehyde ketones & $0.063 \pm 0.003^{a}$ & $0.061 \pm 0.004^{a}$ & $0.054 \pm 0.003^{b}$ & $0.060 \pm 0.004^{a b}$ & $0.017 \pm 0.001^{b}$ & $0.045 \pm 0.011^{a b}$ & $0.054 \pm 0.006^{\mathrm{ab}}$ \\
\hline 3-Octanone & $0.037 \pm 0.002^{\mathrm{b}}$ & $0.052 \pm 0.004^{\mathrm{a}}$ & $0.037 \pm 0.002^{\mathrm{b}}$ & $0.023 \pm 0.003^{\mathrm{c}}$ & & $0.021 \pm 0.002^{\text {cd }}$ & $0.017 \pm 0.003^{\mathrm{d}}$ \\
\hline Benzaldehyde & $0.009 \pm 0.000^{\mathrm{c}}$ & $0.014 \pm 0.001^{\mathrm{d}}$ & $0.010 \pm 0.000^{\mathrm{e}}$ & $0.028 \pm 0.001^{\mathrm{a}}$ & $0.017 \pm 0.001^{\mathrm{cd}}$ & $0.024 \pm 0.004^{\mathrm{ab}}$ & $0.023 \pm 0.001^{\mathrm{b}}$ \\
\hline Damascenone & $0.014 \pm 0.002^{\mathrm{a}}$ & & $0.007 \pm 0.001^{\mathrm{b}}$ & $0.009 \pm 0.000^{\mathrm{ab}}$ & & $0.014 \pm 0.005^{\mathrm{a}}$ & $0.014 \pm 0.002^{\mathrm{a}}$ \\
\hline Phenols & $0.077 \pm 0.001^{a}$ & $0.038 \pm 0.007^{c}$ & $0.033 \pm 0.005^{b c}$ & $0.032 \pm 0.006^{b c}$ & $0.039 \pm 0.001^{b}$ & $0.033 \pm 0.005^{b c}$ & $0.075 \pm 0.002^{a}$ \\
\hline 4-Hydroxy-3-methoxystyrene & & $0.008 \pm 0.001^{\mathrm{a}}$ & $0.007 \pm 0.000^{\mathrm{ab}}$ & $0.009 \pm 0.001^{\mathrm{a}}$ & & $0.005 \pm 0.001^{\mathrm{c}}$ & $0.006 \pm 0.001^{\mathrm{bc}}$ \\
\hline 2,4-Di-tert-butylphenol & $0.077 \pm 0.001^{\mathrm{a}}$ & $0.030 \pm 0.006^{\mathrm{d}}$ & $0.025 \pm 0.005^{\mathrm{d}}$ & $0.023 \pm 0.006^{\mathrm{d}}$ & $0.039 \pm 0.001^{\mathrm{c}}$ & $0.028 \pm 0.004^{\mathrm{d}}$ & $0.069 \pm 0.001^{\mathrm{b}}$ \\
\hline Others & $0.043 \pm 0.003^{a b}$ & $0.017 \pm 0.006^{b c}$ & $0.015 \pm 0.007^{b c}$ & $0.016 \pm 0.001^{c}$ & $0.012 \pm 0.001^{c}$ & $0.048 \pm 0.031^{a}$ & $0.027 \pm 0.002^{a b c}$ \\
\hline 2-Acetylfuran & & & $0.007 \pm 0.000^{\mathrm{b}}$ & $0.008 \pm 0.000^{\mathrm{b}}$ & $0.007 \pm 0.001^{\mathrm{b}}$ & $0.015 \pm 0.003^{\mathrm{a}}$ & $0.008 \pm 0.001^{\mathrm{b}}$ \\
\hline Benzothiazole & $0.043 \pm 0.003^{\mathrm{a}}$ & $0.017 \pm 0.006^{\mathrm{c}}$ & $0.012 \pm 0.001^{\mathrm{cd}}$ & $0.004 \pm 0.000^{\mathrm{e}}$ & $0.005 \pm 0.000^{\mathrm{de}}$ & $0.025 \pm 0.005^{\mathrm{b}}$ & $0.011 \pm 0.002^{\mathrm{cd}}$ \\
\hline 1-Decene & & & & $0.004 \pm 0.001^{\mathrm{c}}$ & & $0.033 \pm 0.003^{\mathrm{a}}$ & $0.008 \pm 0.000^{\mathrm{b}}$ \\
\hline
\end{tabular}

Different letters within the same horizontal line indicate significant difference $(P<0.05)$

\section{Volatile Compounds Analysis}

Qualitative analysis of the HS-SPME/GC-MS results indicate 24 aroma compounds identified from the seven varieties of single fermentation and mixed fermentation jujube juice including esters (7), acids (4), alcohols (5), aldehyde ketones (3), phenols (2) and others (3) in this study (Table 3). Most of these compounds had been reported before in coffee (Lee et al., 2016), red kidney beans (Mishra et al., 2017) and jujube brandy. The ester contents of jujube juice fermented by JM-13+G-1 were significantly higher than those of other juices except JM$17+\mathrm{G}-1(P<0.05)$. In addition, jujube juice fermented by JM-13+G-1 and JM-17+G-1 had higher contents of ethyl caprylate, ethyl caprate and ethyl 3-phenylpropionate. Some esters, such as ethyl caproate, ethyl 9-decenoate and ethyl laurate, were not detected in the control. In particular, JM-17+G-1 has the highest acid and alcohol content relative to the slightly lower contents of jujube juice fermented with strains G-1+JM-13. Octanoic acid, decanoic acid and phenylethyl alcohol were detected in all seven varieties of jujube juice and they presented fattylike, sour-like aroma and rose flower (Chen et al., 2018), respectively. Acetic acid and heptanoic acid were detected in single fermentation by JM-13 and JM-17 and all mixed fermentation jujube juices. Furthermore, damascenone was detected in all jujube juices except JM-3 and JM$3+\mathrm{G}-1$. Carboxylic acids can bind to sugars as esters to contribute to the formation of fruits and vegetables flavour. Esters synthesized through the oxidation of fatty acids contribute to the fruity and floral flavour of jujube (Chen et al., 2018). The six important aroma compounds mentioned above were detected in jujube juice with JM$13+\mathrm{G}-1$. Hence, mixed fermentation with $S$. cerevisiae $\mathrm{JM}-13+\mathrm{G}-1$ is suitable for jujube juice fermentation.

\section{Conclusion}

In this study, nineteen strains of yeasts were isolated from various stages of jujube liquor spontaneous solidstate fermentation. Three strains were selected and identified as $S$. cerevisiae strains to improve the flavour quality of jujube liquor. Strain JM-13 was screened for jujube liquor brewing through the environmental tolerance test and simulated fermentation of jujube juice by commercial S. cerevisiae G-1 and the three identified strains. The inoculation of yeast strain JM-13+G-1 led to produce more abundant ester compounds and higher ester content during jujube juice simulated fermentation. However, our tests were based on the liquid fermentation of jujube juice and the application of JM-13 to solid state fermentation should be further studied in the future work.

\section{Funding Information}

This work was financially supported by project of "Research and pilot test on key technology of quality improvement of jujube distilled liquor" (Award number 
18237122D) and "Agricultural Product Processing Technology Innovation Center of Hebei Province, China" (199676183H).

\section{Author's Contributions}

Xiaolei Guan and Yao Lu: Has contributed in the experiment, paper writing and publication.

Suwen Wang, JingyuJin and Rongbin Li: Have assisted in the experiment.

Yaqiong Liu, Jie Wang: Has contributed in the experiment design and revised the manuscript.

\section{Ethics}

There are not any ethical issues to declare that could arise after the publication of this manuscript. The authors declare that they have no competing interests.

\section{References}

Ballesteros, M., Oliva, J. M., Negro, M. J., Manzanares, P., \& Ballesteros, I. (2004). Ethanol from lignocellulosic materials by a simultaneous saccharification and fermentation process (SFS) with Kluyveromyces marxianus CECT 10875. Process Biochemistry, 39(12), 1843-1848.

Birch, R. M., \& Walker, G. M. (2000). Influence of magnesium ions on heat shock and ethanol stress responses of Saccharomyces cerevisiae. Enzyme and microbial technology, 26(9-10), 678-687.

Chen, Q., Song, J., Bi, J., Meng, X., \& Wu, X. (2018). Characterization of volatile profile from ten different varieties of Chinese jujubes by HSSPME/GC-MS coupled with E-nose. Food Research International, 105, 605-615.

Diaz-Camino, C., Risseeuw, E. P., Liu, E., \& Crosby, W. L. (2003). A high-throughput system for two-hybrid screening based on growth curve analysis in microtiter plates. Analytical biochemistry, 316(2), 171-174.

Duan, C. (2012). Wine yeast selection in Turpan area and it is application in red globe grape sweet wine fermentation. Northwest A\&F University.

Fan, A., Yuan, W., Zhang, H., Xue, X., Qi, X., \& Miao, C. (2012). Determination of aromatic components in chardonnay alcoholic fermentation by static headspace-GC-MS. China Brewing, 3, 047.

González Álvarez, M., González-Barreiro, C., CanchoGrande, B., \& Simal-Gándara, J. (2011). Relationships between Godello white wine sensory properties and its aromatic fingerprinting obtained by GC-MS. Food Chemistry, 129(3), 890-898.

Guo, M. X., Cheng, X. W. and Yu, Y. W. (2019). Effects of different fermentation starter on jujube wine fermentation quality. China Brewing, 38, 58-64.

Hong, L. (2006). On the actuality, existing problems and solutions to the industry of the China jujube. Shanxi Normal University.
Hu, K., Jin, G. J., Xu, Y. H., \& Tao, Y. S. (2018). Wine aroma response to different participation of selected Hanseniaspora uvarum in mixed fermentation with Saccharomyces cerevisiae. Food Research International, 108, 119-127.

Huang, J. Y., Li, X. J., \& Pan, S. Y. (2012). Application of Solid-phase Microextraction in Food Flavor Analysis: A Review [J]. Food Science, 7.

Jia, Q., Zhu, J. B. and Ding, Y. (2015). Study on the brewing yeast selected of jujube wine. Food Industry, 36, 49-52.

Jia, Z. Y., Yan, Z. K., \& Ren, J. M. (2019). Screening of yeast and optimization of fermentation process of jujube wine. Liquor-Making Sci. Technol, 11, 97-101.

Kim, D. H., Lee, S. B., Jeon, J. Y., \& Park, H. D. (2019). Development of air-blast dried non-Saccharomyces yeast starter for improving quality of Korean persimmon wine and apple cider. International journal of food microbiology, 290, 193-204.

Lee, L. W., Cheong, M. W., Curran, P., Yu, B., \& Liu, S. Q. (2016). Modulation of coffee aroma via the fermentation of green coffee beans with Rhizopus oligosporus: I. Green coffee. Food Chemistry, 211, 916-924

Li, S. G., Mao, Z. Y., Wang, P., Zhang, Y., Sun, P. P., Xu, Q., \& Yu, J. (2016). Brewing Jujube Brandy with D aqu and Yeast by Solid - State Fermentation. Journal of Food Process Engineering, 39(2), 157-165.

Li Shuping, Qiu Shiqi, Wu Wanqin, Zhang Ying, Li Shanshan, Li Meiping, \& Zhang Shengwan. (2017). Analysis of flavor components of red date brandy by gas chromatography-smell-mass spectrometry. Food Science, 38 (4), 187-191.

Mishra, P. K., Tripathi, J., Gupta, S., \& Variyar, P. S. (2017). Effect of cooking on aroma profile of red kidney beans (Phaseolus vulgaris) and correlation with sensory quality. Food chemistry, 215, 401-409.

Moreno, A. D., Ibarra, D., Fernández, J. L., \& Ballesteros, M. (2012). Different laccase detoxification strategies for ethanol production from lignocellulosic biomass by the thermotolerant yeast Kluyveromyces marxianus CECT 10875. Bioresource technology, 106, 101-109.

Muenduen, P., Srirattana, N., \& Tanthapanichakoon, W. (2006). Mathematical modeling to investigate temperature effect on kinetic parameters of ethanol fermentation. Biochemical engineering journal, 28(1), 36-43.

Pu, B., Zhang, Y., Liu, Y., \& Liu, X. Y. (2011). Optimization of SPME extraction conditions for aroma components of loquat wine. Food Ferment. Industries, 37, 114-119.

Qi, X. R. (2018). Study on aroma components and fungal diversity during the fermentation of jujube brandy. Hebei Agricultural University.

Quan, Y., Zhang, W., Li, C., \& Wang, S. (2004). Study on the selection of yeasts for brewing jujube wine. Food Ferment. Industries, 11, 39-41. 
Ren, X., Suo, R., Pei, X., Wang, J., Wang, J., Zhang, S., \& Xie, L. (2019). Sensomics characterization of the key odorants in jujube brandy. Shipin Kexue/Food Science, 40(4), 199-205.

SAC, (2016). GB standards. Standardization Administration of China.

Settanni, L., Sannino, C., Francesca, N., Guarcello, R., \& Moschetti, G. (2012). Yeast ecology of vineyards within Marsala wine area (western Sicily) in two consecutive vintages and selection of autochthonous Saccharomyces cerevisiae strains. Journal of bioscience and bioengineering, 114(6), 606-614.

Song, C. H., Sun, X. F., Wang, Y., Liu, Y. Q. and Wang, J. (2019). Change of volatile flavouring components in jujube brandy during fermentation process. Liquor-Making Sci. Technol, (06), 35-40.

SSB, 2018. http://data.stats.gov.cn/search. htm?s=\%E 7\% BA\%A2\%E6\%9E\%A32018>

Suzzi, G., Arfelli, G., Schirone, M., Corsetti, A., Perpetuini, G., \& Tofalo, R. (2012). Effect of grape indigenous Saccharomyces cerevisiae strains on Montepulciano d'Abruzzo red wine quality. Food research international, 46(1), 22-29.

Wang, C., Wu, C., \& Qiu, S. (2019). Yeast diversity investigation of Vitis davidii Föex during spontaneous fermentations using culture-dependent and high-throughput sequencing approaches. Food Research International, 126, 108582.

Wang, C. Y. (2019a). Screening and application of esterproducing yeast from fen-flavour Chinese baijiu. Shanxi University.

Wang, Y. Y. (2019b). Study on fermentation technology of Proso millet yellow rice wine by liquefying method. Northwest A\&F University.
Wang, Q. K., Sun, Z. G., \& Qing, C. (2015). Screening and fermentation properties of yeast for jujube wine. China Brewing, 34, 103-108.

Wang, Y., Wang, J., Liu, Y. Q., Liu, Z., \& Fan, J. F. (2012). Determination of aroma components in distilled fermented apple pomace wine by head space solid phase microextraction (HS - SPME) and GC - MS. Food Science, 33, 205-209.

Xia, Y. N., Shu, Y., Zhao, R. B., \& Wang, J. (2014). The selection of solid phase microextraction fiber in the extraction of aroma components from jujube brandy. J. Chinese Institute Food Sci. Technol, 14, 241-251.

Xia, Y. N., Ma, Y. L., Liu, Y., Shu, Y., \& Wang, J. (2015). Analysis on Flavor Compounds of Jujube Brandy during Distillation by HS-SPMEGC/MS, E-nose and E-tongue. Advance Journal of Food Science and Technology, 8(9), 612-621.

Xin, S. B. (2018). Breeding of high quality Saccharomyces cerevisiae and weaponizing of direct fermentation agent. Nei Menggu Agricultural University.

Zhang, L., Zhang, L., Yu, Z., Xu, Y., \& Li, H. (2018). Isolation and fermentation characteristics of Saccharomyces cerevisiae. Henan Agric. Sci, 47, 144-148.

Zhang, M. X., Wu, Y. W., \& Duan, C. Q. (2008). Research progress in analytic methods of grape and grape wine aroma. Liquor-Making Sci. Technol, 6, 95-98.

Zou, B., Xu, Y. J., \& Xiao, G. S. (2019). Effect of different Saccharomyces cerevisiae on Jun-jujube wine fermentation characteristics. J. Food Sci. Technol, 37, 63-69.

Supplementary Table 1: Volatile compound profile of jujube juice simulated fermentation produced by 19 isolated yeast strains

\begin{tabular}{|c|c|c|c|c|c|c|c|c|c|c|c|c|c|c|c|c|c|c|c|c|}
\hline Compounds $(\mathrm{mg} / \mathrm{L})$ & Control & JM-1 & JM-2 & JM-3 & JM-4 & JM-5 & JM-6 & JM-7 & JM-8 & JM-9 & JM-10 & JM-11 & JM-12 & JM-13 & JM-14 & JM-15 & JM-16 & $5 \mathrm{JM}-17$ & JM-18 & JM-19 \\
\hline Esters & 0.071 & 0.861 & 0.725 & 1.350 & 0.687 & 0.817 & 0.750 & 0.797 & 0.483 & 0.619 & 0.579 & 0.529 & 0.427 & 0.816 & 0.222 & 0.007 & 0.443 & 1.073 & 0.364 & 0.637 \\
\hline Ethyl caproate & & 0.027 & 0.020 & 0.055 & 0.034 & 0.024 & 0.033 & & & 0.033 & & & & & 0.034 & & 0.023 & 0.073 & 0.021 & 0.032 \\
\hline Ethyl heptanate & & & & 0.004 & 0.005 & & 0.008 & & & 0.007 & & & & 0.006 & 0.004 & & 0.004 & 0.008 & 0.006 & 0.008 \\
\hline Methyl octanoate & & 0.006 & 0.008 & & 0.009 & 0.006 & & & & & & & & 0.007 & & & & & & 0.009 \\
\hline Methyl decanoate & & 0.009 & 0.013 & & 0.014 & 0.007 & & & & 0.004 & 0.004 & 0.003 & 0.005 & 0.007 & 0.003 & & & 0.003 & & 0.006 \\
\hline Ethyl caprate & 0.051 & 0.271 & 0.229 & 0.504 & 0.177 & 0.349 & 0.252 & 0.278 & 0.158 & 0.184 & 0.170 & 0.190 & 0.138 & 0.226 & 0.090 & 0.006 & 0.135 & 0.366 & 0.111 & 0.194 \\
\hline Phenethyl acetate & & 0.057 & 0.050 & 0.051 & 0.053 & 0.040 & 0.036 & 0.027 & 0.035 & 0.043 & 0.060 & 0.018 & 0.027 & 0.026 & & & 0.027 & 0.032 & 0.040 & 0.030 \\
\hline Ethyl laurate & 0.009 & 0.029 & 0.038 & 0.104 & 0.040 & 0.038 & 0.041 & 0.085 & 0.033 & 0.029 & 0.030 & 0.052 & 0.027 & 0.075 & 0.017 & 0.001 & 0.031 & 0.067 & 0.018 & 0.028 \\
\hline 3-methyl-butyl decanoate & & 0.011 & 0.009 & 0.013 & 0.022 & 0.014 & & 0.034 & 0.011 & 0.011 & 0.013 & 0.013 & 0.007 & 0.009 & & & 0.012 & 0.017 & 0.006 & 0.010 \\
\hline Acids & 0.140 & 0.713 & 0.646 & 1.170 & 0.905 & 1.009 & 0.342 & 0.571 & 0.599 & 0.397 & 0.573 & 0.246 & 0.271 & 0.303 & 0.159 & 0.090 & 0.236 & 0.288 & 0.126 & 0.241 \\
\hline Acetic acid & & 0.415 & 0.419 & 0.523 & 0.335 & 0.313 & 0.149 & 0.283 & 0.329 & 0.168 & 0.235 & 0.053 & 0.061 & 0.064 & 0.025 & & 0.049 & 0.046 & 0.029 & 0.049 \\
\hline Caproic acid & 0.037 & 0.056 & 0.059 & 0.084 & 0.069 & 0.078 & & 0.055 & 0.053 & 0.035 & 0.059 & 0.034 & 0.043 & 0.044 & 0.029 & 0.037 & 0.036 & 0.039 & 0.026 & 0.036 \\
\hline Hexano & 0.003 & & & & & 0.004 & & & & & 0.005 & & & & & 0.002 & & & & \\
\hline Octanoic acid & 0.012 & 0.142 & 0.118 & 0.306 & 0.296 & 0.343 & 0.113 & 0.141 & 0.131 & 0.113 & 0.167 & 0.089 & 0.102 & 0.112 & 0.047 & 0.008 & 0.084 & 0.115 & 0.042 & 0.092 \\
\hline Decanoic acid & 0.088 & 0.099 & 0.050 & 0.256 & 0.206 & 0.269 & 0.080 & 0.093 & 0.086 & 0.080 & 0.108 & 0.069 & 0.066 & 0.082 & 0.058 & 0.042 & 0.068 & 0.088 & 0.028 & 0.063 \\
\hline Alcohols & 0.015 & 0.868 & 0.865 & 0.740 & 1.395 & 0.474 & 0.775 & 0.595 & 0.732 & 1.243 & 1.654 & 1.005 & 1.180 & 1.310 & & & & & & \\
\hline 3-methyl-1-butanol & & & & & 0.936 & & & & & 0.609 & 0.856 & 0.635 & 0.670 & 0.626 & & & 0.593 & 0.624 & 0.631 & 0.622 \\
\hline Heptanol & & & & & & & & & & 0.004 & 0.005 & 0.005 & 0.006 & 0.006 & & & 0.005 & 0.005 & 0.005 & 0.006 \\
\hline 1-Octanol & & & & 0.007 & 0.006 & 0.007 & & & & & 0.004 & 0.004 & 0.003 & 0.003 & 0.002 & & 0.003 & 0.003 & 0.003 & \\
\hline Aldehyde ketones & 0.018 & 0.016 & 0.009 & 0.006 & 0.000 & 0.000 & 0.011 & 0.013 & 0.012 & 0.011 & 0.013 & 0.012 & 0.011 & 0.017 & 0.013 & 0.020 & 0.014 & 0.018 & 0.013 & 0.014 \\
\hline 3-Octanone & 0.018 & 0.011 & 0.009 & & & & 0.011 & 0.013 & 0.012 & 0.011 & 0.009 & 0.012 & 0.011 & 0.011 & 0.013 & 0.017 & 0.014 & 0.013 & 0.013 & 0.014 \\
\hline Damascenone & & 0.005 & & 0.006 & & & & & & & 0.004 & & & 0.006 & & 0.003 & & 0.005 & & \\
\hline Phenols & 0.010 & 0.014 & 0.011 & 0.019 & 0.017 & 0.016 & 0.017 & 0.007 & 0.012 & 0.011 & 0.018 & 0.004 & 0.009 & 0.008 & 0.002 & 0.002 & 0.010 & 0.012 & 0.006 & 0.009 \\
\hline $\begin{array}{l}\text { 4-Hydroxy-3- } \\
\text { methoxystyrene }\end{array}$ & & 0.010 & 0.011 & 0.010 & 0.011 & 0.011 & 0.008 & & 0.006 & 0.006 & 0.009 & & 0.006 & 0.005 & & & 0.005 & 0.006 & 0.003 & 0.006 \\
\hline 2,4-Di-tert-butylphenol & 0.010 & 0.004 & & 0.009 & 0.006 & 0.006 & 0.009 & 0.007 & 0.007 & 0.005 & 0.009 & 0.004 & 0.004 & 0.003 & 0.002 & 0.002 & 0.005 & 0.006 & 0.003 & 0.004 \\
\hline
\end{tabular}

